\title{
CULTURE AND COSMOS
}

A Journal of the History of Astrology and Cultural Astronomy

Vol. 13 no. 1, Spring/Summer 2009

Published by Culture and Cosmos and the Sophia Centre Press,

in partnership with the University of Wales Trinity Saint David, in association with the Sophia Centre for the Study of Cosmology in Culture,

University of Wales Trinity Saint David, Faculty of Humanities and the Performing Arts Lampeter, Ceredigion, Wales, SA48 7ED, UK.

\section{www.cultureandcosmos.org}

Cite this paper as: Patrick Curry, 'Response to Liz Greene, "Is Astrology a Divinatory System?"', Culture and Cosmos, Vol. 13 no 1, Spring/Summer 2009, pp. 76-79.

British Library Cataloguing in Publication Data

A catalogue card for this book is available from the British Library

All rights reserved. No part of this book may be reproduced or utilized in any form or by any means, electronic or mechanical, including photocopying, recording or by any information storage and retrieval system, without permission in writing from the Publishers.

\section{ISSN 1368-6534}

Printed in Great Britain by Lightning Source

Copyright (C) 2018 Culture and Cosmos All rights reserved 


\section{Correspondence}

\section{Response to Liz Greene, 'Is Astrology a Divinatory System?'}

\section{Patrick Curry}

Dr Greene raises many interesting issues in her wide-ranging paper in Vol. 12 no 1, and I am not going to try to address them all. ${ }^{1}$ However, I feel compelled to respond to some, especially where my own work has been directly addressed by her and where I have some competence. In a few cases, I think my work has not been represented entirely accurately; in most, I welcome the opportunity to clarify my position.

To begin with, I don't think the lack of a clear definition of divination should be used to say that, when it isn't or wasn't explicitly identified as such, it was absent. Nor can such a lack be used to suggest (which Greene comes close to doing) that the phenomenon itself is therefore incoherent or faulty. That lack is more likely to suggest, as it does in the case of astrology, a rich and complex phenomenon which resists exhaustive summary.

Regarding the difference(s) between divinatio and mantikê, it would be linguistic essentialism to argue that there can be no common ground in what surely matters most-their uses and therefore meanings-simply because the words themselves differ qua words. And her main point, that there is no explicit 'divine' in the latter of the two, seems contradicted by her remark that 'mantikê has a connection with theos (god)'.

Incidentally, the same paragraph describes 'the chief characteristic of the true diviner' as 'temporary possession by a deity'. ${ }^{3}$ I cannot agree and, based on my own research and what I know of others', doubt that that statement could be adequately supported. Divination as I understand and have defined it, at any rate, involves questioning, and ideally a dialogue with, divinity, but certainly not possession by it.

I also disagree that 'the ability to predict the future [is] an essential element in divination' or divinatory astrology. ${ }^{4}$ It may be a common

1 Liz Greene, 'Is Astrology a Divinatory System?', Culture and Cosmos, Vol. 12 no 1, Spring/Summer 2008, pp. 3-29.

2 Ibid., p. 9.

3 Ibid.

4 Ibid., p. 12. 
demand made of diviners, and sometimes a claim by them (the more ignorant or incautious), but for reasons I discuss in chapter five of my Astrology, Science and Culture (ASC) and my Carter Memorial Lecture, 'Astrology, Divination and Enchantment', my position (quoting from the latter) is that 'prediction is not essential to astrology', and 'future divinatory astrology involves not prediction but advice. 5

On another point, am I guilty of invoking divination as a single 'master principle' when it comes to astrology? I'm genuinely not sure, but I don't think so. I don't say that everything magical or occult in the broadest sense (let alone everything else, which is the kind of claim a real monist would make) is divination; I am only concerned with astrology. And informally speaking, my claim takes this form: everything essential-or important (a weaker claim) - or interesting about astrology (an even weaker claim! but one still worth making) is divinatory. I'm aware, of course, that each of these three versions requires making a somewhat different case or, in terms of the case I have already made in ASC, a different variant-not something I am going to do here. It is also true that each one raises a host of new questions. But that is perfectly normal, indeed unavoidable, so it's hardly a damning point. Nor am I putting forward one Truth to rule them all, but rather what I see as an interesting, fruitful, creative perspective; $a$ way to inhabit astrology and bring it to life in a manner that is both ancient and, in our time, new. (Or it was new, when Geoffrey Cornelius raised it in 1994. And let me add that I don't believe there can be any really serious or thorough discussion of astrology as divination that excludes his Moment of Astrology, which is the key text in the debate. ${ }^{6}$ )

Greene suggests that in astrology, the empirically predictable movements of the planets means that there is an absence of randomisation (a key element in divination) which differentiates the two. In ASC, I argue that randomisation is present not only in horary astrology-when a moment is chosen for the question without the positions of the planets known so as to determine which moment is chosen-but also natal astrology, insofar as the moment of birth is clearly itself a 'random'

5 Roy Willis and Patrick Curry, Astrology, Science and Culture: Pulling Down the Moon, Oxford: Berg, 2004; 'Astrology, Divination and Enchantment', http://www.skyscript.co.uk/enchantment.html.

6 Geoffrey Cornelius, The Moment of Astrology (London: Arkana, 1994).

Culture and Cosmos 
moment (from a human point-of-view, which is what all such 'randomness' assumes). In any consultation, furthermore, there is far too much information present in the nativity to all be included, so a selection of what is significant is an absolute requirement; but that selection is not itself entirely determined by the planetary positions in the map. And as I suspect all practising astrologers (including Greene) know, because they have experienced it, that in the correct choice and communication of the precisely relevant symbolism, something else is present and participating that is also not 'in' the map. Now if astrologers want to try to make what they are doing safely secular, they can call this 'unconscious intuition' or some such name if they want, but in my opinion doing so (a) certainly will not work, and (b) is intellectually suspect, because it fails to respect the decidedly non-modern, non-secular and non-safe quality of the phenomenon... which calling it 'divination' does. (In case it's not already clear, I am talking about the practice of astrology. Considered solely as a theory, it may indeed be a 'symbolic meaning system' or something similar.)

On a technical point, my words 'no direct spiritual input or dimension' did not apply to Alan Leo but as the text itself shows, to Ptolemy and Aristotle's cosmology. ${ }^{7}$ And, speaking of Ptolemy, his work cannot be understood without taking into consideration the context for its production and reception. With that in mind, it is clear that the Tetrabiblos was a rhetorical and programmatic performance aimed at establishing the dominance of a particular kind of astrology, one that was 'scientific' and non-divinatory. It cannot be taken purely at face value, as if Ptolemy was just describing what astrology is, or even what his own astrology consisted of (to the exclusion of anything else). There is also no reason to assume that Ptolemy's astrology was typical of his time and place compared to that of Valens, say, which was much more (openly?) divinatory.

Finally, Greene challenges my rhetorical question in ASC posing horoscopic astrology as divinatory by asking, 'What is there important about this situation [an astrological consultation] that is not psychological?' Now I appreciate that a skilled practitioner of psychological astrology brings something unique and valuable to an astrological consultation. I also certainly agree that the participation of the human psyche is indispensable. To that extent, she is right.

7 Greene, 'Is Astrology a Divinatory System?,', p. 23, citing Willis and Curry, Astrology, Science and Culture, p. 74.

Culture and Cosmos 
Nonetheless, it seems to me that there is a serious problem with using psychology as the central or defining concept for understanding or describing such events.

That problem follows from the clear implication that the entire process (or at least the important or interesting parts of it) is intra-psychic: that it is taking place within the human mind. To me that seems quite wrong, in the sense of inaccurate, in both of the ways that my italicisation emphasizes. Phenomenologically speaking, whatever is going on in such situations seems better described by David Abram's term 'more-thanhuman': including, but exceeding, the human, and as much 'outer' as it is 'inner'. Furthermore, psychology as any kind of ultimate context implicitly connives with the extremely damaging Cartesian division into human mind (formerly spirit) on the one hand and world (including body) on the other. Whether philosophically, ethically, or politically, that is completely unacceptable. (Not least because that very split, as it hardened, almost became the death-knell for an astrological cosmos!)

The only way to avoid these consequences and retain 'psychological' as central is to interpret that word, together with 'mind', as itself morethan-human; which is indeed what Jung tried to do with his neologism 'psychoid'. But in that case, why use the word in the first place, if to do so requires such special pleading and contorted logic? As well as matching closely what the experience feels like, 'divinatory' avoids those consequences without any contortions, which is why I prefer it. 